\title{
Identification of resistance loci in Chinese and Canadian canola/rapeseed varieties against Leptosphaeria maculans based on genome-wide association studies
}

\author{
Fuyou Fu ${ }^{1,2}$, Xuehua Zhang ${ }^{1}$, Fei Liu', Gary Peng ${ }^{2}$, Fengqun $\mathrm{Yu}^{2^{*}}$ and Dilantha Fernando ${ }^{1 *}$ (D)
}

\begin{abstract}
Background: The fungal pathogen Leptosphaeria maculans $(L \mathrm{~m})$. causes blackleg disease on canola/rapeseed in many parts of the world. It is important to use resistant cultivars to manage the disease and minimize yield losses. In this study, twenty-two $\mathrm{Lm}$ isolates were used to identify resistance genes in a collection of 243 canola/rapeseed (Brassica napus L.) accessions from Canada and China. These $L m$ isolates carry different compliments of avirulence genes, and the investigation was based on a genome-wide association study (GWAS) and genotype-by-sequencing (GBS).

Results: Using the CROP-SNP pipeline, a total of 81,471 variants, including 78,632 SNPs and 2839 InDels, were identified. The GWAS was performed using TASSEL 5.0 with GLM + Q model. Thirty-two and 13 SNPs were identified from the Canadian and Chinese accessions, respectively, tightly associated with blackleg resistance with $P$ values $<1 \times$ $10^{-4}$. These SNP loci were distributed on chromosomes A03, A05, A08, A09, C01, C04, C05, and C07, with the majority of them on A08 followed by A09 and A03. The significant SNPs identified on A08 were all located in a 2010-kb region and associated with resistance to 12 of the $22 \mathrm{Lm}$ isolates. Furthermore, 25 resistance gene analogues (RGAs) were identified in these regions, including two nucleotide binding site (NBS) domain proteins, fourteen RLKs, three RLPs and six TM-CCs. These RGAs can be the potential candidate genes for blackleg resistance.
\end{abstract}

Conclusion: This study provides insights into potentially new genomic regions for discovery of additional blackleg resistance genes. The identified regions associated with blackleg resistance in the germplasm collection may also contribute directly to the development of canola varieties with novel resistance genes against blackleg of canola.

Keywords: Genotyping-by-sequencing (GBS), Genome-wide association study (GWAS), Resistance gene analogues (RGAs), Brassica napus, Leptosphaeria maculans, Blackleg, Phoma stem canker

\section{Background}

Brassica napus L. (AACC, $2 \mathrm{n}=38$ ) is one of the important crop used for oil, vegetable, fodder, and bio-fuel [1-4]. Blackleg (Phoma stem canker), caused by the fungal pathogen Leptosphaeria maculans is one of the major diseases on

\footnotetext{
*Correspondence: fengqun.yu@canada.ca; Dilantha.fernando@umanitoba.ca ${ }^{2}$ Saskatoon Research Centre, Agriculture and Agri-Food Canada, 107 Science Place, Saskatoon, Saskatchewan S7N 0X2, Canada

'Department of Plant Science, University of Manitoba, Winnipeg, MB R3T 2N2, Canada
}

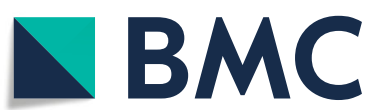

(c) The Author(s). 2020 Open Access This article is licensed under a Creative Commons Attribution 4.0 International License, which permits use, sharing, adaptation, distribution and reproduction in any medium or format, as long as you give appropriate credit to the original author(s) and the source, provide a link to the Creative Commons licence, and indicate if changes were made. The images or other third party material in this article are included in the article's Creative Commons licence, unless indicated otherwise in a credit line to the material. If material is not included in the article's Creative Commons licence and your intended use is not permitted by statutory regulation or exceeds the permitted use, you will need to obtain permission directly from the copyright holder. To view a copy of this licence, visit http://creativecommons.org/licenses/by/4.0/ The Creative Commons Public Domain Dedication waiver (http://creativecommons.org/publicdomain/zero/1.0/) applies to the data made available in this article, unless otherwise stated in a credit line to the data. Prior research has determined that $L$ maculans can cause severe infection on a susceptible canola cultivar and reduce the seed yield by more than 50\% [5]. Improving resistance to $L$. maculans is one of the major objectives in canola breeding programs in Canada, especially due to the fact that the disease is difficult to control with fungicides [6].

Two types of resistance to $L$. maculans have been reported in B. napus [7]; qualitative resistance mediated by 
an effector-triggered immunity (ETI) mechanism with specialized interactions between a race-specific $\mathrm{R}$ protein and corresponding avirulent (Avr) protein. Currently, $\mathrm{R}$ gene resistance is the most effective method against blackleg in canola, and $19 \mathrm{R}$ genes have been identified in B. rapa, B. juncea, B. napus, and B. nigra [8-16]. However, the pathogen populations have also been rapidly evolving, with high selection pressure, due to broad utilization of single-gene resistance in commercial fields. This results in rapid erosion of resistance as the pathogen population evolves. In Australia, LepR3 resistance derived from $B$. rapa subsp. sylvestris was overcome within 3 years after the commercial release of the cultivars [17]. Rouxel et al. [18] also reported that the frequency of AvrLm1 was rapidly decreased due to the increased commercial use of the $R \operatorname{lm} 1$ resistance gene in France. In western Canada, a few studies have revealed that the structure of $L m$ population has been shifting over the past decade; PG2 was classified as the primary pathogenicity group (PG) of $\mathrm{Lm}$ collected between 1984 and $2000[19,20]$, but PG3 and PGT emerged from $\mathrm{Lm}$ isolates collected between 1998 and 2004. Liban et al. provided further evidence on a shift in avirulence allele frequencies in $L m$ isolates collected in 2010 and 2011 [21]. Zhang et al. reported that $R \operatorname{lm} 3$ resistance had been broken down because AvrLm 3 was no longer a predominant avirulence effector in western Canada [22]. These studies indicate that the $L m$ population has evolved with the selection pressure from resistant canola varieties which carry a limited number of resistance genes; a single $\mathrm{R}$ gene will unlikely provide durable resistance against highly diverse $L m$ races in western Canada. Continued efforts to identify novel resistance loci from canola or rapeseed germplasm can aid in blackleg resistance breeding by providing new resistance sources for disease management. Another type of resistance is quantitative resistance $(\mathrm{QR}$, race non-specific), which is conferred typically by patterntriggered immunity (PTI) mechanisms in conjunction with pathogen associated molecular patterns [23, 24]. Several QR loci have been identified for resistance to $\mathrm{Lm}$ using traditional QTL and/or genome wide association studies (GWAS) approaches on the genetic/physical maps of B napus [25-35]. Darmor-bzh/Yudal (DY) [25, 26, 34, 35], Topas/AG-Castle (TC) and Topas/AV-Sapphire (TS) [26-28], Skipton/Ag-Spectrum (SASDH) [32] DH population and a few diverse panels $[26,30]$ of $B$.napus were employed to identify QR loci for blackleg resistance in canola. However, Canadian and Chinese canola germplasm has not been used to identify QR or QTL against the diverse Canadian $L m$ population.

China imports a substantial amount of canola/rapeseed seed, meal and oil from countries like Canada and Australia each year [36]. Since the pathogen $L m$ has not been reported in China, the inoculum on imported canola seeds is deemed a risk of introduction [37]. In fact, blackleg has been closely monitored in China [38], with disease surveys conducted frequently. So far the results have indicated that blackleg in China is caused exclusively by $L$. biglobosa [36-40], a less aggressive species of Leptosphaeria. It may be useful to minimize $\mathrm{Lm}$ contamination of seed/dockage for export to China [41], identification of resistance genes in Chinese varieties will also assist in Chinese scientists to develop effective resistant cultivars quickly once $L m$ is found in the country.

Association mapping (AM) has been used as a powerful tool to overcome some of the limitations of bi-parental mapping for QTL discoveries [42, 43]; it can reduce the time lag between QTL discoveries and marker-assisted selection (MAS) [44], especially with a huge number of SNP markers identified with next generation sequencing. AM (also referred to as linkage disequilibrium mapping) is the non-random association between molecular markers and a phenotypic trait in a collection of genetically diverse germplasm [45]. Historic recombination between a marker and the locus associated with the trait of interest is exploited to uncover significant correlations between markers and phenotypic traits. Therefore, genome-wide association studies offers scanning of marker-trait associations using moderate marker densities, whereas fine mapping is achieved through subsequent mapping with higher density markers $[43,46]$. AM has been successfully employed to map complex traits in plants, including disease resistance, such as resistance to Pseudomonas syringae in Arabidopsis thaliana [47], Stagonospora nodorum blotch in wheat [48], stem rust resistance in barley [49], bymovirus in barley [50] and fusarium head blight in barley [51]. In a well-designed association mapping study, newly discovered QTLs could immediately be used for MAS. In B. napus, AM mapping of complex traits has focused mostly on oil $[52,53]$ and glucosinolate [54] content, phenolic compounds [55] and agronomic traits $[52,56]$. Jestin et al. [30] used AM to map QTLs for resistance to blackleg caused by Lm in B. napus. AM with genotyping-by-sequencing (GBS) has been widely used to map QTLs in crops. GBS can generate millions of SNPs using next generation sequencing technologies with low cost $[57,58]$. We have successfully mapped three QTL for clubroot resistance to six pathotypes of Plasmodiophora brassicae in Brassica rapa with GBS [59]. In this study, new resistance accessions were identified during screening for blackleg resistance in a world collection of 243 B. napus. Meanwhile, potential new blackleg resistance loci were found with genome-wide association study using GBS.

\section{Results}

Genetic variation in resistance to $L$. maculans

Total of $22 \mathrm{Lm}$ isolates were employed to assess the resistance of 243 canola accessions at the seedling (cotyledon) stage. The Avr-gene compliments of the isolates 
have been reported previously $[22,60]$ and are listed in Table S1. Both Canadian accessionsand Chinese accessions presented quantitive trait characterization among of $22 \mathrm{Lm}$ isolates and five field trials (Fig. 1). Extensive variation was observed among the accessionstested for the resistance; the lesion score ranged from 1 to 9 among both Canadian and Chinese accessions on cotyledons, with the majority of them being susceptible (lesion scores $>5$ ) to all the $L m$ isolates, especially those from China (Fig. 1a and b).

\section{Identification of DNA variants}

A total of 243 B. napus accessions collected from China and Canada $[22,60]$ were analysed with the GBS method on an Illumina HiSeq 2500 (PE125) system (Table S2), with a total of 1054 million reads generated. Based on the output of GBS-SNP-CROP pipeline V3.0 [61], a total of 81,471 high-quality DNA variants (78,632 SNPs and 2839 InDels) were identified using the $B$. napus reference genome [62] under the parameters described in Methods, (Fig. 2a). InDels were not considered for GWAS in this study. The number of variants was significantly correlated
( $P=0.000574$, Spearman correlation) with the length of chromosomes (Fig. 2b). All variants were converted into plink and hmnp in Tassel format using the scripts of the GBS-SNP-CROP pipeline v3.0 [61] for further GWAS.

\section{GWAS identified resistance loci to $L$. maculans}

A total of 16,503 SNP loci were obtained after filtering at MAF $>5 \%$ and missing data $<10 \%$, and then used for GWAS using general linear model (GLM) with two methods GLM + Principal component analysis (PCA) and $\mathrm{GLM}+(\mathrm{Q})$. The results fromGLM+PCA GLM + Q were very similar. Additionly, no difference was found in the significant SNP loci identified from orginal phenotypic data and from nomoralized data (data not shown). Hence, in this study, GLM $+Q$ module with original phenotypical data was performed as identify the significantly associated SNP loci.

GWAS identified loci for cotyledon resistance to $L$. maculans in Canadian canola accessions.

Resistance loci in Canadian and Chinese canola accessions against $L$. maculans were dissected at both seedling and adult-plant stages using GWAS in TASSEL 5.0
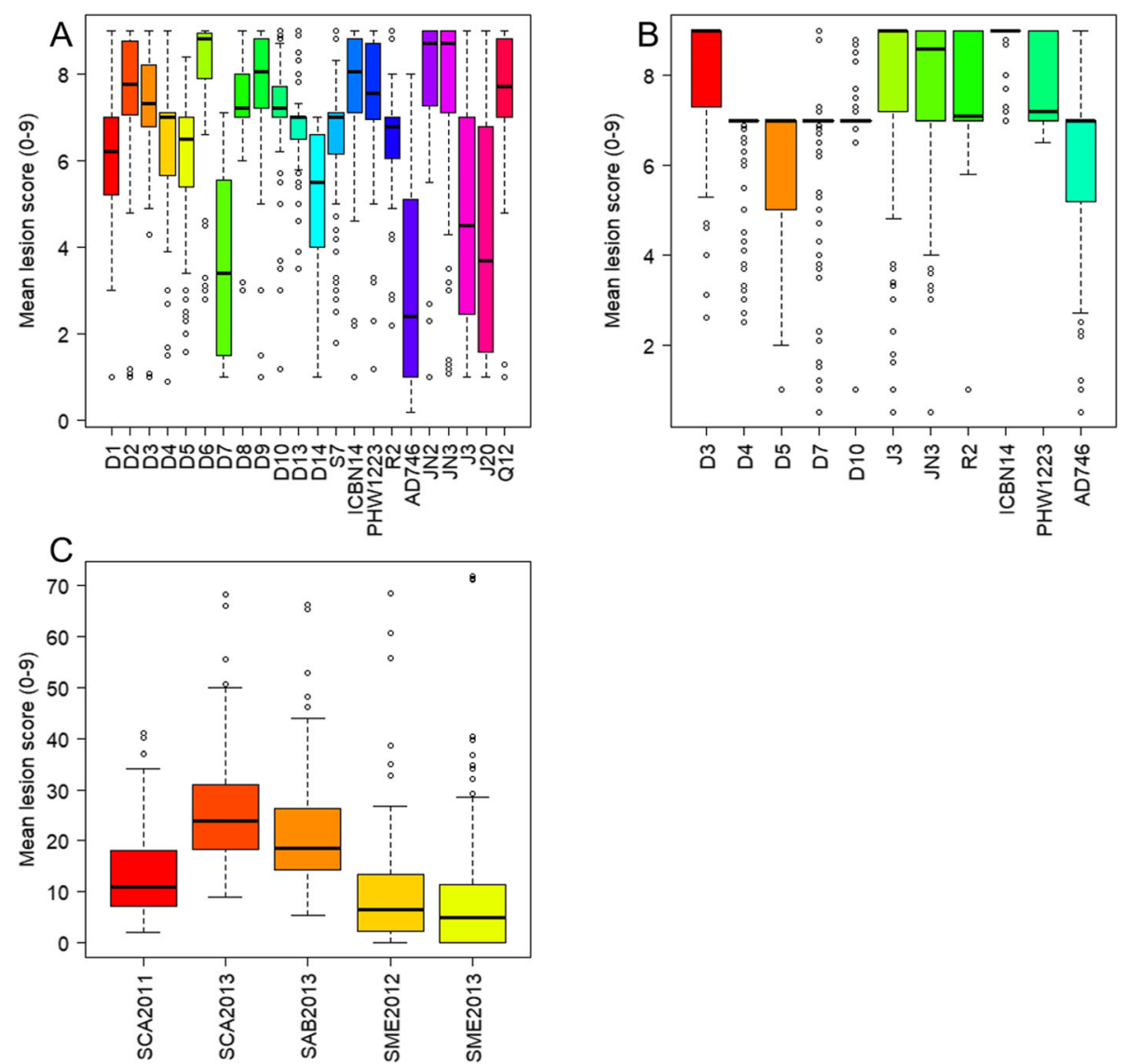

Fig. 1 Phenotypic variation for reistance to L. maculans. a Box-plots showing seeding phenotypic variation to $22 \mathrm{~L}$. maculans isolates in 93 Canadian accessions. b Box-plots showing seeding phenotypic variation to $12 \mathrm{~L}$. maculans isolates in 150 Chinese accessions. c Box-plots showing phenotypic variation in 150 Chinese accessions with five field trials 

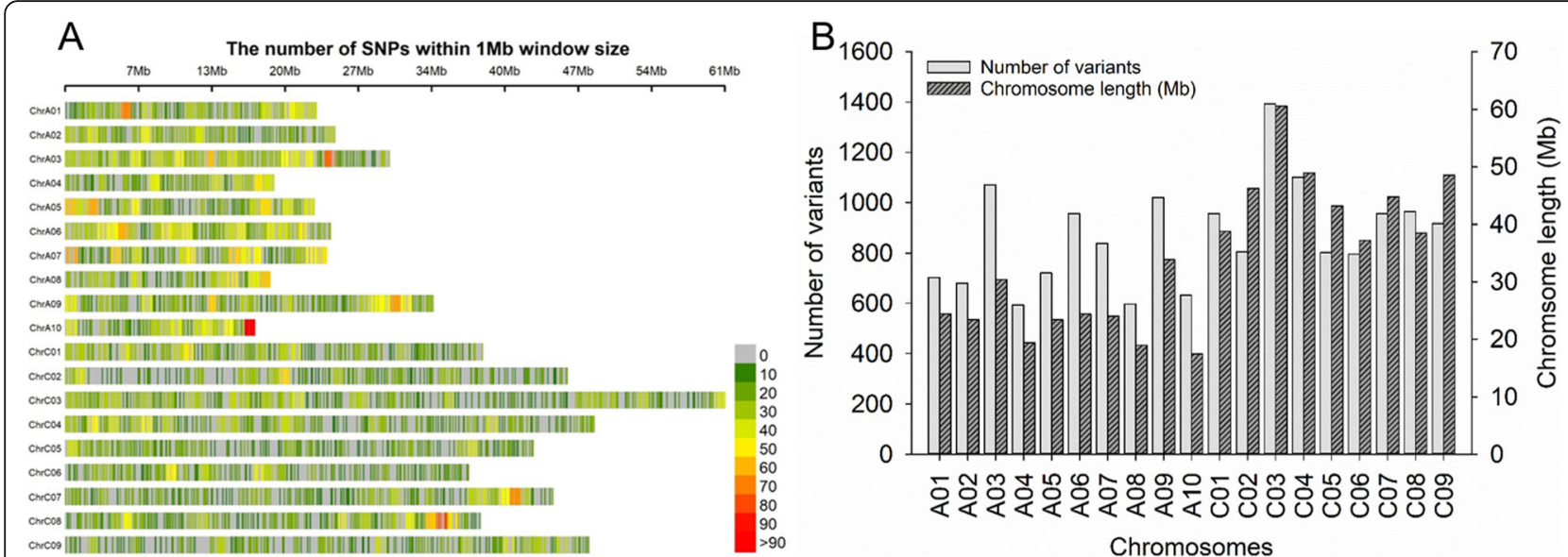

Fig. 2 The distrubition of variants (SNPs and InDels) each chromosome based on B. napus reference genome. a Number of SNPs within 1 Mb windows size in each chromosome. b Number of plolymorphic variants (SNPs and InDels) in each chromosome

with GLM + Q. A total of 111 significant loci were identified with 22 isolates in Canadian varieties, with 12.1$31.6 \%$ phenotypic variations explained by resistance loci (Table S2). These associated-resistance loci were mostly located on chromosomes A03, A08 and A09 (Fig. 3a and Fig. 4), with 30 of them identified repeatedly against multiple $\mathrm{Lm}$ isolates (Table S2). On chromosome A03, three SNPs (delimited with 24,158,622 | A > C, 24717825 | $\mathrm{T}>\mathrm{C}$, and 24,731,214 $\mid \mathrm{C}>\mathrm{T}$, respectively) were located within a 572-kb region. Four SNPs $(6,430,433$ | $\mathrm{C}>\mathrm{G}, 6430461|\mathrm{~T}>\mathrm{A}, 6430502| \mathrm{T}>\mathrm{C}$, and 6,441,932 | $\mathrm{G}>\mathrm{T}$, respectively) were detected within an $11-\mathrm{kb}$ region on chromosome A08. Two SNPs $(30,423,813 \mid \mathrm{C}>$ $\mathrm{T}$ and $30,423,849 \mid \mathrm{T}>\mathrm{G}$ ) were found within a very narrow region ( $36 \mathrm{bp}$ ) on chromosome A09. No resistance loci were detected from these Canadian varieties at the seedling stage against 6 of the $L m$ isolates (D7, D13, D14, AD746, J3 and J20) at $P<10^{-4}$.

A total of 57 significant SNP loci were identified against the $12 \mathrm{Lm}$ isolates in Chinese canola accessions with 9.1$24.3 \%$ phenotypic variation in resistance (Table S3). These resistance-associated SNP loci were mostly located on chromosomes A08, C01, C04, C05 and C07 (Fig. 3b and Fig. 4), with 35 of them identified repeatedly against multiple isolates (Table S2). Most of theassociated SNPs were detected with isolate D10; 35 SNPs were located on chromosomes A08, C01, C04, C05 and C07.

On chromosome A08, 6 SNPs $(6,986,581 \mid \mathrm{G}>\mathrm{C}$, $6986629|\mathrm{~A}>\mathrm{T}, 6986688| \mathrm{A}>\mathrm{T}, 6986854 \mid \mathrm{T}>\mathrm{G}$, $6986868 \mid \mathrm{C}>\mathrm{T}, 6986893$ | A $>$ G) were identified within a narrow region $(312 \mathrm{bp})$. On chromosome $\mathrm{C} 01$, there were also 6 SNPs $(14,069,868|\mathrm{C}>\mathrm{T}, 14069974| \mathrm{T}>\mathrm{C}$, $14087080|\mathrm{~A}>\mathrm{T}, 14087137| \mathrm{A}>\mathrm{G}, 14090999 \mid \mathrm{G}>\mathrm{A}$ and 14,091,013 $\mid \mathrm{A}>\mathrm{C}$ ) that were detected in a 21-kb region. Four SNPs $(47,531,363 \mid$ A $>$ G, $47531439 \mid$ G $>$ A,
$47531442 \mid \mathrm{T}>\mathrm{C}$ and 47,531,461 | G > C) were found in a 98-bp region on chromosome C04. Twelve SNPs (20,249, $568|\mathrm{G}>\mathrm{T}, 20452502| \mathrm{A}>\mathrm{C}, 20452533 \mid \mathrm{G}>\mathrm{A}$, $20452554 \mid$ A $>$ C, $20599157|\mathrm{C}>\mathrm{A}, 20599238| \mathrm{G}>\mathrm{A}$, $21291258|\mathrm{C}>\mathrm{T}, 21291283| \mathrm{T}>\mathrm{C}, 21637008 \mid \mathrm{T}>\mathrm{C}$, $21637016|\mathrm{~A}>\mathrm{C}, 21637090| \mathrm{T}>\mathrm{A}$, and 21,564,255 |A > G) were located in two regions $(147 \mathrm{~kb}$ and $346 \mathrm{~kb}$, respectively) on chromosome C05. Twelve SNPs (37,421, $042|\mathrm{~T}>\mathrm{C}, 37421119| \mathrm{C}>\mathrm{A}, 37421931 \mid \mathrm{G}>\mathrm{C}$, $37583190|\mathrm{~T}>\mathrm{A}, 37583265| \mathrm{C}>\mathrm{T}, 37583295 \mid \mathrm{T}>\mathrm{G}$, $37583379 \mid \mathrm{T}>\mathrm{C}$ ) were located within a 162-kb region on chromosome $\mathrm{C} 07$.

A total of 13 significantly-associated loci were identified based on the resistance rating in 5 field trials in western Canada, with $8.7-18.7 \%$ phenotypic variation in resistance (Table S4). These resistance loci were located on chromosomes A01 (17,731,177 | A > G), C01 (12,182, $933 \mid \mathrm{A}>\mathrm{G}), \mathrm{C} 03(18,318,846 \mid \mathrm{T}>\mathrm{C}$ and 23,396,866 | A > G) and C07 (33,405,386 | A >C) (Fig. 3c and Fig. 4).

\section{Potential resistance gene analogues against $L$. maculans in B. napus}

A total of 2821 RGA candidates were identified and classified into four major families based on the combinations of these RGA domains and motifs with the RGAugury pipeline [63] in the B. napus reference genome [62], including 627 NBS-encoding proteins, 1503 receptor-like kinases (RLKs), 276 receptor-like proteins (RLPs) and 415 transmembrane coiled-coil proteins (TM-CC) (Table S5). These RGAs were evenly distributed on 19 B. napus chromosomes (Fig. 5 and S1).

Twelve associated regions were identified within 200 $\mathrm{kb}$ from the most significant SNP loci associated with the resistance, including three, four and five regions in the cotyledon stage of Canadian and Chinese varieties and adult-plant stage of Chinese varieties, respectively 

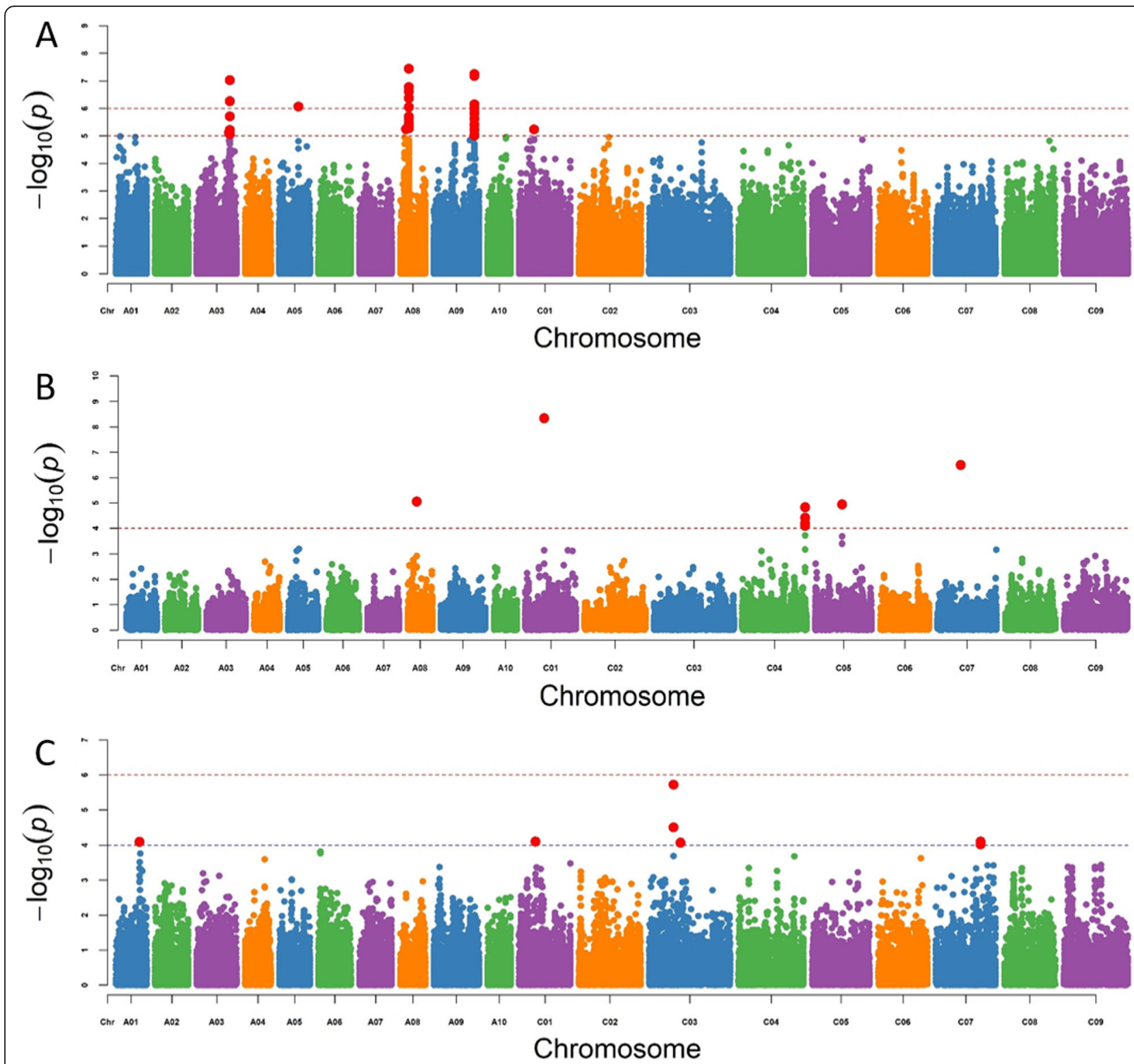

Fig. 3 Manhattan plots showing the results of genome-wide association study for resistance to L. maculans with seedling and adult-plant stages in Canadian and Chinese accessions. Red dots present significant SNPs with $P$ value $<1 \times 10^{-5}$ in Canadian germplasm and $1 \times 10^{-4}$ in Chinese germplasm. Dash line present the threshold values. a shows significant SNPs in 93 Canadian accessions. b shows significant SNPS in 150 Chinese accessions. $\mathbf{c}$ shows significant SNPs in Chinese accessions with five field trials

(Table 1). Twenty-five RGAs were identified in these regions, including two NBS-domain proteins, fourteen RLKs, three RLPs and six TM-CCs.

\section{Discussion}

Previous studies have shown that $L m$ populations evolve rapidly under the selection pressure from resistant canola/rapeseed cultivars carrying specific $R$ genes [21, 22], and single $R$ genes can be overcome due to the high diversity of $L m$ and a shift of pathogen population toward virulence [22]. Hence, it is critical for the canola industry to continue identifying novel alleles of resistance for sustainable management of blackleg. The GWAS allow us to rapidly identify and validate significant loci with associated markers. In this study, twelve associated regions were identified from B. napus, including 93 Canadian and 150 Chinese canola/rapeseed accessions, against 22 $\mathrm{Lm}$ isolates, under controlled-environment and/or field experiments. Some race nonspecific QTLs were identified in this study. For example, resistance-associated region on Chromosome A08 from Canadian varieties was effective against 15 of the $22 \mathrm{Lm}$ isolates (Table S2 and 


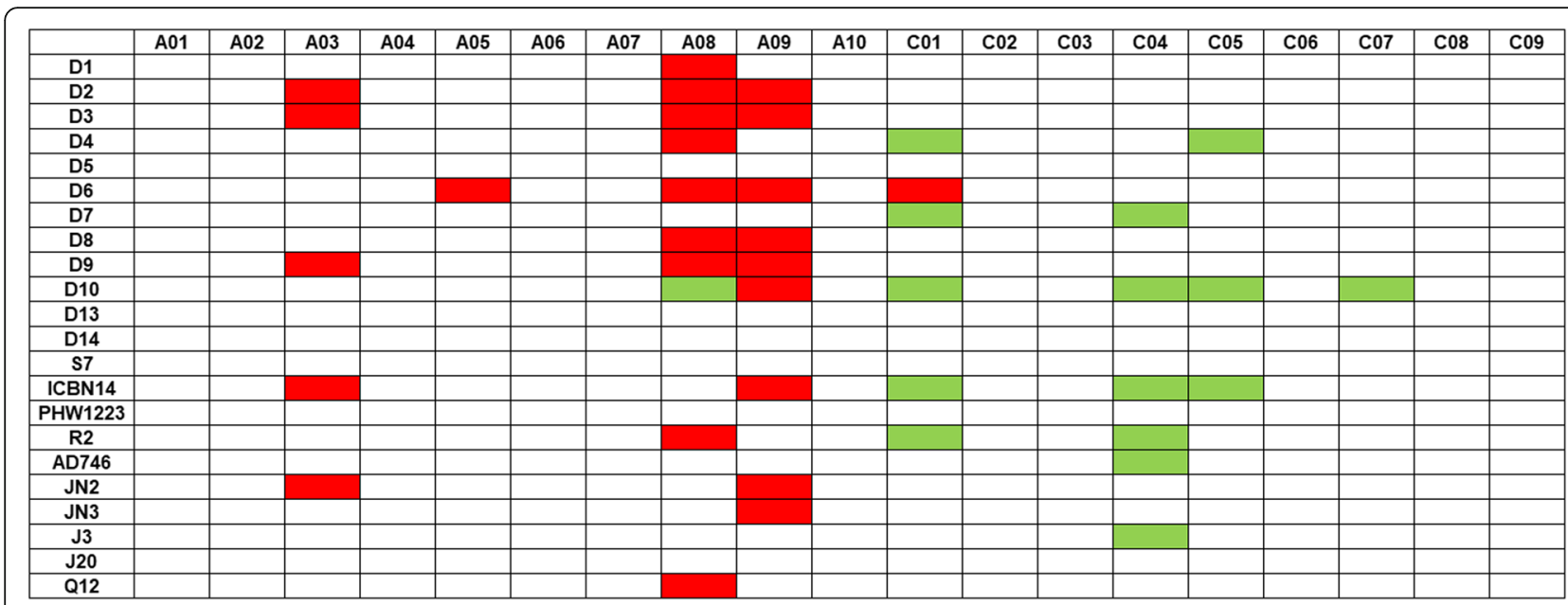

Fig. 4 Summary of the resistance loci in Candian and Chinese accessions. Red box presents the loci in Canadian accessions. Green box presents the loci in Chinese accessions

Fig. 4). These significant regions with resistance to a broad range of $L m$ races are considered potential alleles with greater durability for blackleg resistance.

Three most significant resistance-associated regions, identified among Canadian accessions against $22 \mathrm{Lm}$ isolates based on cotyledon inoculation, were on chromosomes A03, A08 and A09 (Table S2). However, the known R genes Rlm1, Rlm2, Rlm3, Rlm4-7, Rlm6, LepR1, LepR2 or LepR3 were not detected in these significant SNP loci based on the Avr genes carried by the $\mathrm{Lm}$ isolates used in the study. Our results show that the resistance alleles identified can be novel or they may interact with known $\mathrm{R}$ loci and produce new resistance specificity. Quantitative resistance has been identified on chromosomes A03, A08 and A09 previously [25-27, 29, $30,34]$. In this study, three associated SNP loci were found in a 572-kb region on chromosome A03 $(24,158$, 622 to $24,701,214)$. One SNP and one QTL were identified also on chromosome A03 from studies of 179

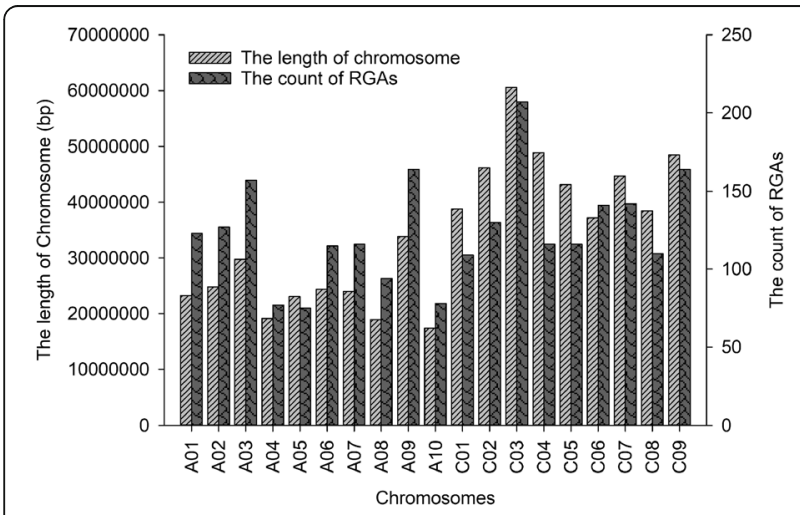

Fig. 5 The distrubition of RGAs each chromosome based on $B$. napus reference genome
Table 1 Potential resistance gene analogues against $L$. maculans in B. napus

\begin{tabular}{|c|c|c|c|c|}
\hline Accessions & $\mathrm{Chr}$ & Position & candidate genes & Protein family \\
\hline \multirow[t]{7}{*}{ Canadian } & $\mathrm{A} 03$ & $24,158,622$ & BnaA03g47360D & RLK \\
\hline & & & BnaA03g47390D & TM-CC \\
\hline & & & BnaA03g48410D & RLK \\
\hline & A08 & $6,430,433$ & BnaA08g06440D & RLK \\
\hline & & & BnaA08g07010D & TM-CC \\
\hline & A09 & $30,423,813$ & BnaA09g44200D & RLK \\
\hline & & & BnaA09g44590D & RLK \\
\hline \multirow[t]{8}{*}{ Chinese } & $\mathrm{CO} 1$ & $14,069,868$ & BnaC01g19470D & RLK \\
\hline & & & BnaC01g20530D & TM-CC \\
\hline & $\mathrm{CO} 4$ & $47,531,363$ & BnaC04g49200D & RLK \\
\hline & & & BnaC04g50000D & RLP \\
\hline & C05 & $20,249,568$ & BnaC05g24620D & RLP \\
\hline & & & BnaC05g26730D & RLK \\
\hline & $\mathrm{CO}$ & $37,421,042$ & BnaC07g34000D & $N B S>T N$ \\
\hline & & & BnaC07g35850D & RLK \\
\hline \multirow[t]{10}{*}{ Field } & $\mathrm{A} 01$ & $17,731,177$ & BnaA01g24810D & RLK \\
\hline & & & BnaA01g25640D & RLK \\
\hline & $\mathrm{CO1}$ & $12,182,933$ & BnaC01g16720D & TM-CC \\
\hline & & & BnaC01g18040D & $\mathrm{NBS}>\mathrm{NL}$ \\
\hline & $\mathrm{CO3}$ & $18,318,846$ & BnaC03g29930D & RLK \\
\hline & & & BnaC03g30950D & RLK \\
\hline & $\mathrm{CO3}$ & $23,396,866$ & BnaC03g35640D & TM-CC \\
\hline & & & BnaC03g38180D & TM-CC \\
\hline & $\mathrm{CO}$ & $33,405,386$ & BnaC07g27490D & RLK \\
\hline & & & BnaC07g28950D & RLP \\
\hline
\end{tabular}


Australia accessions [26] and linkage mapping of a "Darmor-bzh" x "Yudal" DH population [29], respectively, but these regions appear far away from the resistance-associated regions identified in the current study. Significant SNP loci or QTLs associated with cotyledon or adultplant resistance have also been identified on chromosomes A08 and A09 using an association panel [30], DH [25, 27, 29] or $F_{2} / F_{3}$ Canola/rapeseed populations [34]. However, these loci were detected using Australian or French materials based on genetic-linkage maps with SSRs or other markers, and it is difficult to determine physical positions of these SNPs/QTLs precisely against the B. napus reference genome. In this study, we were able to narrow the range of resistance-associated SNP loci to an 11-kb region on chromosome A08 and $36 \mathrm{bp}$ on chromosome A09, respectively, using GBS with $B$. napus reference genome for the resistance on cotyledons. This shows the advantage of using GWAS and GBS to identify resistance loci against blackleg disease of canola/rapeseed.

Five resistance-associated regions were located on chromosomes A08, C01, C04, C05 and C07 in the Chinese rapeseed accessions against $12 \mathrm{Lm}$ isolates on cotyledons (Table S3). On chromosome A08, however, the physical position of the region appears different from that found with Canadian canola accessions. Although these regions have not been reported previously for $\mathrm{Lm}$ resistance at the seeding stage, the associated SNP loci were located in homologous regions, especially on chromosomes A01/C01, A04/C04/A05, C07/A03/C03. These regions may either reside functionally redundant loci or be involved in increased allelic diversity of the genes controlling the resistance to blackleg [33].

Our results showed that there were less number of QTLs against L. maculans identified from the Chinese accessions than the Canadian accessions, and also SNPs associated with cotyledon resistance to $L$. maculans were distributed in both $\mathrm{A}$ and $\mathrm{C}$ genomes of $B$. napus from the Chinese accessions, but mainly in the A genome from the Canadian accessions. One of the reasons for these could be due to different breeding focuses for resistance to canola diseases between the two countries. The selection and accumulation of canola against $L$. maculans have never been performed in canola breeding programs in China. Chinese accessions are winterecotype [64], and blackleg, caused by L. maculans has never been an issue in the canola growing areas in China. Hence, breeding for resistance to L. maculans has not been considered as one of the breeding objectives by Chinese canola breeders. On the other hand, $L$. maculans is an important disease on canola in western Canada. Great efforts have been made for breeding canola for resistance to blackleg in the past 3 years. Introgression of resistance genes derived from the A-genome species B. rapa, such as LEM1 [65], LmFr1 [66], LmR1/
CLmR1 [67, 68], Rlm1, Rlm3, Rlm4, Rlm7 and $R \operatorname{lm} 9$ [15, 66-69], and LepR1 to LepR4 [12-14] have been performed. Therefore, it would not be surprising that more QTLs were identified in the Canadian accessions and the resistance loci were mainly distributed in A genome of B. napus.

The completely sequenced and annotated genome of B. napus provides a useful reference to identify blackleg resistance candidate genes in canola/rapeseed germplasm pools. Plant resistance genes, such as CC-LRRNBS, TIR-LRR-NBS, RLK, RLP and transmembrane proteins, can all be identified using the RGAugury pipeline [63]. Several potentially new $R$ gene candidates were uncovered from the Canadian and Chinese canola/rapeseed accessions using genome-wide studies with the RGA pipeline, and these candidates have also been located close to the significant SNPs identified in GWAS, and can be potential blackleg-resistance genes supported by robust genetic and genomic analyses. They should be further explored for confirmation and applications. It is interesting to note that many of the well-known blackleg $\mathrm{R}$ genes, including $R \operatorname{lm} 1, R \operatorname{lm} 3$ and $L e p R 3 / R \operatorname{lm} 2$, were not detected with GWAS in this study. This may be due to a lack of marker polymorphism in the mapping panel because of selected commercial varieties, such as the Canadian panel, has only moderate genome-wide coverage of makers and low frequencies of informative alleles (associated with blackleg resistance). Additionally, the Chinese panel was not selected originally for blackleg resistance, since the causal agent $L m$ had not been reported in China. The blackleg resistance loci identified in this study appear novel, and the study provides insights into several potentially new regions for discovery of additional blackleg $\mathrm{R}$ genes.

\section{Conclusion}

In this study, twenty-two Lm isolates were used to identify resistance genes in a collection of 243 canola/rapeseed (Brassica napus L.) accessions from Canada and China. Thirty-two and 13 SNPs were identified from the Canadian and Chinese accessions, respectively, tightly associated with blackleg resistance with $P$ values $<1 \times$ 10-4 using a genome-wide association study (GWAS) and genotype-by-sequencing (GBS). These SNP loci were distributed on chromosomes A03, A05, A08, A09, $\mathrm{C} 01, \mathrm{C} 04, \mathrm{C} 05$, and $\mathrm{C} 07$, with the majority of them on A08 followed by A09 and A03. Our study provides insights into potentially new genomic regions for discovery of additional blackleg resistance genes. The identified regions associated with blackleg resistance in the germplasm collection may also contribute directly to the development of canola varieties with novel resistance genes against blackleg of canola. 


\section{Plant source}

Out of 150 Chinese B. napus accessions, 136 accessions were kindly provided by Prof. Baocheng $\mathrm{Hu}$ from Anhui Academy of Agricultural Sciences, Hefiei, Anhuhi, China, and 14 accessions were kindly provided by Prof. Yingze Niu from Sichuan Agricultural University, Chengdu, Sichuan Province, China.

\section{Methods}

Blackleg resistance evaluation using multiple $\mathrm{Lm}$ isolates

A diverse panel of 243 accessions of $B$. napus, including 93 Canadian canola varieties or breeding lines [22] and 150 Chinese canola varieties [60], was evaluated for seedling resistance against $22 \mathrm{Lm}$ isolates with different compliments of Avr genes. Cotyledon inoculation assay was used to evaluate seedling resistance of 243 canola accessions under controlled environment $\left(21^{\circ} \mathrm{C} / 16^{\circ} \mathrm{C}\right.$ with a $16 \mathrm{~h}$ photoperiod). Briefly, seven-day-old canola seedlings were punctured and inoculated with $10 \mu \mathrm{L} \mathrm{Lm}$ pycnidiospore suspension $\left(2 \times 10^{7}\right.$ spores $\left./ \mathrm{mL}\right)$. Lesion size on the cotyledons was scored 12-14 days post inoculation using the rating scale of 0-9 [22]. The average rating score (ARS)) was calculated from 48 inoculation sites. The interaction phenotype was evaluated as follows: $\mathrm{ARS} \leq 4.5$ was considered resistant reaction (R), ARS = 4.6-6.0 was intermediate reaction (I) and ARS = 6.1-9.0 was susceptible reaction (S) [22]. Details of Avr gene composition have been described previously for these isolates $[22,60]$. All phenotypic data were performed on non-normalization and normalization anlysis based on previously published method [70].

\section{Reference-based SNP calling}

Leaf-tissue samples were collected from true leaf of canola/rapeseed seedlings, freeze-dried in a Freezone 6 dryer (Labconco Corp, Kansas City, MO) for $48 \mathrm{~h}$, then ground using the Mixture Mills 300 (Retsch Inc., Newtown, PA). DNA was isolated using a DNeasy 96 Plant Kit (Qiagen, Toronto, ON), quantified using a NanoVue Plus spectrophotometer (GE Healthcare, Piscataway, NJ), diluted to $10 \mathrm{ng} \mathrm{Hl}^{-1}$ and kept at $-20^{\circ} \mathrm{C}$ until use in subsequent genotyping.

Raw 125-bp pair-end reads, with low-quality reads and adapters removed, were trimmed using Trimmomatic $[71,72]$ of the GBS-SNP-CROP pipeline V3.0 [61]. The filtered reads were aligned to the $B$. napus reference genome [62] using the Burrows-Wheeler Aligner program V0.7.12 [73] and GBS-SNP-CROP pipeline v3.0 [61]. For SNP calling and filtering, the GBS-SNP-CROP pipeline v3.0 [61] was used. SNPs and InDels were filtered with the following parameters: $\mathrm{mnHoDepth} 0=11$, mnHoDepth $1=48, \quad$ mnHetDepth $=3, \quad$ altStrength $=0.9$, mnAlleleRatio $=0.1, \mathrm{mnCall}=0.75, \mathrm{mnAvgDepth}=3$ and mxAvgDepth $=200$.
Population structure (Q) and kinship coefficients (K)

To determine the $\mathrm{Q}$ value of population structure accurately, STRUCTURE 2.3.3 [74] (http://pritch.bsd.uchicago.edu/software.html) was performed with 503 selected SNPs, which were evenly distributed with $5 \mathrm{Mb}$ intervals on each chromosome of $B$. napus. In STRUCT URE 2.3.3, the admixture ancestry and independent allele frequency parameters were used in the model with a burn-in period of 100,000 and a Markov chain Monte Carlo Model (MCMC) with 100,000 repetitions as suggested by Pritchard and Wen [75]. It was assumed that sub-populations (K) were set to 1-10, with 20 independent iterations run for each $K$. The obtained Q-matrices were used to assign $B$. napus lines to defined subpopulations. Structure Harvester v6.7 [76] was used to determine the number of sub-populations according to Evanno et al. [77]. Finally, the Q-matrices were determined with CLUMPP (V1.1.2b) [78].

The population structure was verified by PCA using kinship coefficients among lines with SNP and InDel genotypic data (filtered for 5\% minor allele frequency) for the 243 canola/rapeseed lines in TASSEL 5.0 [79].

\section{Genome-wide association studies}

The association of SNP and InDel markers with blackleg resistance was examined in TASSEL 5.0 [79]; all markers were filtered for $5 \%$ minor allele frequency (MAF) and $10 \%$ missing genotypes and the filtered genotyping data were used for association analysis. The kinship matrix (K) and Principal Component Analysis (PCA) were estimated using filtered SNPs in TASSEL 5.0. Both general linear models (GLM) (GLM + Q and GLM + PCA) and mixed linear models (MLM) (MLM + Q + K and MLM + $\mathrm{PCA}+\mathrm{K})$ were performed to investigate best fit models in the current study. Additional, original and normalized phenotypic data were ananlyzed using the above four model. A positive false discovery rate (pFDR) of $5 \%(q<$ 0.05) [80] was applied to test the statistical significance of all detected SNP loci. The phenotypic traits of SNP marker alleles were calculated as the difference between the mean phenotypes of the two marker classes (presence or absence of marker alleles) in TASSEL 5.0. RGA candidates were identified with the RGAugury pipeline [63] in the B. napus reference genome [62].

\section{Supplementary information}

Supplementary information accompanies this paper at https://doi.org/10. 1186/s12864-020-06893-4.

Additional file 1.

Additional file 2.

Additional file 3.

Additional file 4.

Additional file 5. 


\section{Additional file 6 .}

\section{Abbreviations}

CV: Coefficient of variation; GBS: Genotype-by-sequencing; FDRs: False discovery rates; GLM: General linear model; GWAS: Genome-wide association study; Lm: Leptosphaeria maculans; RGAs: Resistance gene analogues; LOD: Logarithm of odds; RLKs: Receptor-like kinases; RLPs: Receptor-like proteins; TM-CC: Transmembrane coiled-coil proteins; AM: Association mapping; MAS: Marker-assisted selection; QR: Quantitative resistance; ETI: Effector-triggered immunity; PG: Pathogenicity group (PG); NBS: Nucleotide binding site; MLM: Mixed linear model; PCA: Principal component analysis; QTL: Quantitative trait loci; SNP: Single nucleotide polymorphism

\section{Acknowledgements}

The authors are grateful to Drs. Rui Wang and Qilin Chen for their support on GBS. The authors also wish to thank the critical internal reviews done by James Tucker (AAFC, Brandon, MB), Sajid Reman (ICARDA, Morrocco) and Sanjaya Gyawali (Washington State University, USA).

\section{Authors' contributions}

FY and DF conceived of and designed the study; FF, XZ and FL conducted the experiments; FF analyzed data; GP provided important support. FF drafted the manuscript. All authors reviewed the manuscript and approved the final draft.

\section{Funding}

This work was funded by a competitive grant from SaskCanola under Canola Agronomic Research Program. The funding body played no role in the design of the study and collection, analysis, and interpretation of data and in writing the manuscript.

\section{Availability of data and materials}

The datasets used and/or analyzed during the current study available from the corresponding authors on reasonable request.

\section{Ethics approval and consent to participate}

Not applicable.

\section{Consent for publication}

Not applicable.

\section{Competing interests}

The authors declare that they have no competing interest.

Received: 10 December 2019 Accepted: 7 July 2020

Published online: 21 July 2020

\section{References}

1. Abbadi A, Leckband G. Rapeseed breeding for oil content, quality, and sustainability. Eur J Lipid Sci Technol. 2011;113(10):1198-206.

2. McNaughton IH. Swedes and rapes. In: Smartt J, Simmonds NW, editors. Evolution of crop plants. Harlow: Longman Scientific \& Technical; 1995. p. 68-75.

3. Pavlista AD, Santra DK, Isbell TA, Baltensperger DD, Hergert GW, Krall J, et al. Adaptability of irrigated spring canola oil production to the US High Plains. Ind Crop Prod. 2011;33(1):165-9.

4. Şensöz $S$, Angin D, Yorgun S. Influence of particle size on the pyrolysis of rapeseed (Brassica napus L.): fuel properties of bio-oil. Biomass Bioenergy. 2000;19(4):271-9.

5. Gugel RK, Petrie GA. History, occurrence, impact, and control of blackleg of rapeseed. Can J Plant Pathol. 1992;14(1):36-45.

6. Kutcher HR, Yu F, Brun H. Improving blackleg disease management of Brassica napus from knowledge of genetic interactions with Leptosphaeria maculans. Can J Plant Pathol. 2010;32(1):29-34.

7. Delourme R, Chèvre AM, Brun H, Rouxel T, Balesdent MH, Dias JS, et al. Major gene and polygenic resistance to Leptosphaeria maculans in oilseed rape (Brassica napus). Eur J Plant Pathol. 2006;1 14(1):41-52.

8. Delourme R, Barbetti M, Snowdon R, Zhao J, Manazanares-Dauleux M, Edwards D, et al. Genetics and genomics of disease resistance. Genetics, genomics and breeding of oilseed brassicas. Boca Raton: Science Publishers; 2011. p. 276-318.

9. Marcroft SJ, Elliott VL, Cozijnsen AJ, Salisbury PA, Howlett BJ, Van de Wouw AP. Identifying resistance genes to Leptosphaeria maculans in Australian Brassica napus cultivars based on reactions to isolates with known avirulence genotypes. Crop and Pasture Sci. 2012;63(4):338-50.

10. Balesdent MH, Fudal I, Ollivier B, Bally P, Grandaubert J, Eber F, et al. The dispensable chromosome of Leptosphaeria maculans shelters an effector gene conferring avirulence towards Brassica rapa. New Phytol. 2013;198(3):887-98.

11. Ghanbarnia K, Ma L, Larkan NJ, Haddadi P, Fernando WGD, Borhan MH. Leptosphaeria maculans AvrLm9: a new player in the game of hide and seek with AvrLm4-7. Mol Plant Pathol. 2018;19(7):1754-64.

12. Yu F, Gugel RK, Kutcher HR, Peng G, Rimmer SR. Identification and mapping of a novel blackleg resistance locus LepR4 in the progenies from Brassica napus x B. rapa subsp. sylvestris. Theor Appl Genet. 2013;126(2):307-15.

13. Yu F, Lydiate DJ, Rimmer SR. Identification of two novel genes for blackleg resistance in Brassica napus. Theor Appl Genet. 2005;110(5):969-79.

14. Yu F, Lydiate DJ, Rimmer SR. Identification and mapping of a third blackleg resistance locus in Brassica napus derived from B. rapa subsp. sylvestris. Genome. 2008:51(1):64-72.

15. Fu F, Liu X, Wang R, Zhai C, Peng G, Yu F, et al. Fine mapping of Brassica napus blackleg resistance gene RIm1 through bulked segregant RNA sequencing. Sci Rep. 2019:9(1):14600.

16. Christianson JA, Rimmer SR, Good AG, Lydiate DJ. Mapping genes for resistance to Leptosphaeria maculans in Brassica juncea. Genome. 2006; 49(1):30-41.

17. Sprague SJ, Balesdent M-H, Brun H, Hayden HL, Marcroft SJ, Pinochet X, et al. Major gene resistance in Brassica napus (oilseed rape) is overcome by changes in virulence of populations of Leptosphaeria maculans in France and Australia. Eur J Plant Pathol. 2006;114(1):33-40.

18. Rouxel T, Penaud A, Pinochet X, Brun H, Gout L, Delourme R, et al. A 10year survey of populations of Leptosphaeria maculans in France indicates a rapid adaptation towards the RIm1 resistance gene of oilseed rape. Eur J Plant Pathol. 2003:109(8):871-81.

19. Kutcher HR, van den Berg CGJ, Rimmer SR. Variation in pathogenicity of Leptosphaeria maculans on brassica spp. based on cotyledon and stem reactions. Can J Plant Pathol. 1993;15(4):253-8.

20. Chen Y, Fernando WGD. Prevalence of pathogenicity groups of Leptosphaeria maculans in western Canada and North Dakota, USA. Can J Plant Pathol. 2006;28(4):533-9.

21. Liban SH, Cross DJ, Kutcher HR, Peng G, Fernando WGD. Race structure and frequency of avirulence genes in the western Canadian Leptosphaeria maculans pathogen population, the causal agent of blackleg in brassica species. Plant Pathol. 2016;65(7):1161-9.

22. Zhang X, Peng G, Kutcher HR, Balesdent M-H, Delourme R, Fernando WGD. Breakdown of RIm3 resistance in the Brassica napus-Leptosphaeria maculans pathosystem in western Canada. Eur J Plant Pathol. 2016;145(3): 659-74.

23. Young ND. QTL mapping and quantitative disease resistance in plants. Annu Rev Phytopathol. 1996;34:479-501.

24. Veronese P, Nakagami H, Bluhm B, Abuqamar S, Chen X, Salmeron J, et al. The membrane-anchored BOTRYTIS-INDUCED KINASE1 plays distinct roles in Arabidopsis resistance to necrotrophic and biotrophic pathogens. Plant Cell. 2006;18(1):257-73,

25. Raman H, Raman R, Diffey S, Qiu Y, McVittie B, Barbulescu DM, et al. Stable quantitative resistance loci to blackleg disease in canola (Brassica napus L.) over continents. Front Plant Sci. 2018;9:1622.

26. Raman H, Raman R, Coombes N, Song J, Diffey S, Kilian A, et al. Genomewide association study identifies new loci for resistance to Leptosphaeria maculans in canola. Front Plant Sci. 2016;7:1513.

27. Delourme R, Piel N, Horvais R, Pouilly N, Domin C, Vallée P, et al. Molecular and phenotypic characterization of near isogenic lines at QTL for quantitative resistance to Leptosphaeria maculans in oilseed rape (Brassica napus L.). Theor Appl Genet. 2008;117(7):1055-67.

28. Kaur S, Cogan NOI, Ye G, Baillie RC, Hand ML, Ling AE, et al. Genetic map construction and QTL mapping of resistance to blackleg (Leptosphaeria maculans) disease in Australian canola (Brassica napus L.) cultivars. Theor Appl Genet. 2009;120(1):71-83.

29. Jestin C, Vallée P, Domin C, Manzanares-Dauleux MJ, Delourme R. Assessment of a new strategy for selective phenotyping applied to complex traits in Brassica napus. Open J Genet. 2012;2(4):190. 
30. Jestin C, Lodé M, Vallée P, Domin C, Falentin C, Horvais R, et al. Association mapping of quantitative resistance for Leptosphaeria maculans in oilseed rape (Brassica napus L.). Mol Breed. 2011;27(3):271-87.

31. Raman R, Taylor B, Lindbeck K, Coombes N, Barbulescu D, Salisbury $P$, et al. Molecular mapping and validation of RIm1 gene for resistance to Leptosphaeria maculans in canola (Brassica napus L.). Crop and Pasture Sci. 2012;63(10):1007-17

32. Raman R, Taylor B, Marcroft S, Stiller J, Eckermann P, Coombes N, et al. Molecular mapping of qualitative and quantitative loci for resistance to Leptosphaeria maculans causing blackleg disease in canola (Brassica napus L.). Theor Appl Genet. 2012;125(2):405-18.

33. Fopa Fomeju B, Falentin C, Lassalle G, Manzanares-Dauleux MJ, Delourme R. Homoeologous duplicated regions are involved in quantitative resistance of Brassica napus to stem canker. BMC Genomics. 2014;15(1):498

34. Jestin C, Bardol N, Lodé M, Duffé P, Domin C, Vallée $P$, et al. Connected populations for detecting quantitative resistance factors to phoma stem canker in oilseed rape (Brassica napus L.). Mol Breed. 2015:35(8):167.

35. Kumar V, Paillard S, Fopa-Fomeju B, Falentin C, Deniot G, Baron C, et al. Multi-year linkage and association mapping confirm the high number of genomic regions involved in oilseed rape quantitative resistance to blackleg. Theor Appl Genet. 2018;131(8):1627-43.

36. Liu Z, Latunde-Dada AO, Hall AM, Fitt BDL. Phoma stem canker disease on oilseed rape (Brassica napus) in China is caused by Leptosphaeria biglobosa 'brassicae'. Eur J Plant Pathol. 2014;140(4):841-57.

37. Zhang X, White RP, Demir E, Jedryczka M, Lange RM, Islam M, et al. Leptosphaeria spp., phoma stem canker and potential spread of $\mathrm{L}$. maculans on oilseed rape crops in China. Plant Pathol. 2014;63(3):598-612.

38. West JS, Evans N, Liu S, Hu B, Peng L. Leptosphaeria maculans causing stem canker of oilseed rape in China. Plant Pathol. 2000;49(6):800.

39. Cai X, Huang Y, Jiang D, Fitt BDL, Li G, Yang L. Evaluation of oilseed rape seed yield losses caused by Leptosphaeria biglobosa in Central China. Eur J Plant Pathol. 2018;150(1):179-90.

40. Fitt BDL, Brun H, Barbetti MJ, Rimmer SR. World-wide importance of Phoma stem canker (Leptosphaeria maculans and L. biglobosa) on oilseed rape (Brassica napus). Eur J Plant Pathol. 2006;114(1):3-15.

41. Fernando WGD, Zhang $X$, Amarasinghe CC. Detection of Leptosphaeria maculans and Leptosphaeria biglobosa causing blackleg disease in canola from Canadian canola seed lots and dockage. Plants (Basel, Switzerland). 2016:5(1):12

42. Breseghello F, Sorrells ME. Association mapping of kernel size and milling quality in wheat (Triticum aestivum L.) cultivars. Genetics. 2006;172(2):1165-77.

43. Ingvarsson PK, Street NR. Association genetics of complex traits in plants. New Phytol. 2011;189(4):909-22.

44. Bernardo R. Molecular markers and selection for complex traits in plants: learning from the last 20 years. Crop Sci. 2008;48(5):1649-64.

45. Flint-Garcia SA, Thornsberry JM, Buckler ES. Structure of linkage disequilibrium in plants. Annu Rev Plant Biol. 2003;54:357-74.

46. Rafalski JA. Association genetics in crop improvement. Curr Opin Plant Biol. 2010;13(2):174-80

47. Aranzana MJ, Kim S, Zhao K, Bakker E, Horton M, Jakob K, et al. Genomewide association mapping in Arabidopsis identifies previously known flowering time and pathogen resistance genes. PLoS Genet. 2005;1:5.

48. Tommasini L, Schnurbusch T, Fossati D, Mascher F, Keller B. Association mapping of Stagonospora nodorum blotch resistance in modern European winter wheat varieties. Theor Appl Genet. 2007;115(5):697-708.

49. Steffenson BJ, Olivera P, Roy JK, Jin Y, Smith KP, Muehlbauer GJ. A walk on the wild side: mining wild wheat and barley collections for rust resistance genes. Aust J Agric Res. 2007:58(6):532-44.

50. Stracke S, Presterl T, Stein N, Perovic D, Ordon F, Graner A. Effects of introgression and recombination on haplotype structure and linkage disequilibrium surrounding a locus encoding bymovirus resistance in barley. Genetics. 2007;175(2):805-17.

51. Massman J, Cooper B, Horsley R, Neate S, Dill-Macky R, Chao S, et al. Genome-wide association mapping of fusarium head blight resistance in contemporary barley breeding germplasm. Mol Breed. 2011;27(4):439-54.

52. Honsdorf N, Becker HC, Ecke W. Association mapping for phenological, morphological, and quality traits in canola quality winter rapeseed (Brassica napus L.). Genome. 2010;53(11):899-907.

53. Zou J, Jiang C, Cao Z, Li R, Long Y, Chen S, et al. Association mapping of seed oil content in Brassica napus and comparison with quantitative trait loci identified from linkage mapping. Genome. 2010;53(11):908-16.
54. Hasan M, Friedt W, Pons-Kühnemann J, Freitag NM, Link K, Snowdon RJ. Association of gene-linked SSR markers to seed glucosinolate content in oilseed rape (Brassica napus ssp. napus). Theor Appl Genet. 2008;116(8): 1035-49.

55. Rezaeizad A, Wittkop B, Snowdon R, Hasan M, Mohammadi V, Zali A, et al. Identification of QTLs for phenolic compounds in oilseed rape (Brassica napus L.) by association mapping using SSR markers. Euphytica. 2011;177(3): 335-42.

56. Zhao K, Aranzana MJ, Kim S, Lister C, Shindo C, Tang C, et al. An Arabidopsis example of association mapping in structured samples. PLoS Genet. 2007; 3(1):0071-82.

57. Elshire RJ, Glaubitz JC, Sun Q, Poland JA, Kawamoto K, Buckler ES, et al. A robust, simple genotyping-by-sequencing (GBS) approach for high diversity species. PLoS One. 2011;6(5):e19379.

58. Peterson BK, Weber JN, Kay EH, Fisher HS, Hoekstra HE. Double digest RADseq: an inexpensive method for de novo SNP discovery and genotyping in model and non-model species. PLoS One. 2012;7(5):e37135.

59. Yu F, Zhang X, Peng G, Falk KC, Strelkov SE, Gossen BD. Genotyping-bysequencing reveals three QTL for clubroot resistance to six pathotypes of Plasmodiophora brassicae in Brassica rapa. Sci Rep. 2017;7(1):4516

60. Zhang $X$, Peng G, Parks $P, H u B$, Li Q, Jiang L, et al. Identifying seedling and adult plant resistance of Chinese Brassica napus germplasm to Leptosphaeria maculans. Plant Pathol. 2017;66(5):752-62.

61. Melo AT, Bartaula R, Hale I. GBS-SNP-CROP: a reference-optional pipeline for SNP discovery and plant germplasm characterization using variable length, paired-end genotyping-by-sequencing data. BMC Bioinform. 2016;17:29.

62. Chalhoub B, Denoeud F, Liu S, Parkin IA, Tang H, Wang X, et al. Plant genetics. Early allopolyploid evolution in the post-Neolithic Brassica napus oilseed genome. Science. 2014;345(6199):950-3.

63. Li P, Quan X, Jia G, Xiao J, Cloutier S, You FM. RGAugury: a pipeline for genome-wide prediction of resistance gene analogs (RGAs) in plants. BMC Genomics. 2016;17(1):852.

64. Lu K, Wei L, Li X, Wang Y, Wu J, Liu M, et al. Whole-genome resequencing reveals Brassica napus origin and genetic loci involved in its improvement. Nat Commun. 2019;10(1):1154.

65. Ferreira M, Rimmer S, Williams P, Osborn T. Mapping loci controlling Brassica napus resistance to Leptosphaeria maculans under different screening conditions. Phytopathology. 1995;85(2):213-7.

66. Dion Y, Gugel RK, Rakow GF, Seguin-Swartz G, Landry BS. RFLP mapping of resistance to the blackleg disease [causal agent, Leptosphaeria maculans (Desm.) Ces. Et de not.] in canola (Brassica napus L.). Theor Appl Genet. 1995:91(8):1190-4

67. Mayerhofer R, Good AG, Bansal VK, Thiagarajah MR, Stringam GR. Molecular mapping of resistance to Leptosphaeria maculans in Australian cultivars of Brassica napus. Genome. 1997:40(3):294-301.

68. Mayerhofer R, Wilde K, Mayerhofer M, Lydiate D, Bansal VK, Good AG, et al. Complexities of chromosome landing in a highly duplicated genome: toward map-based cloning of a gene controlling blackleg resistance in Brassica napus. Genetics. 2005;171(4):1977-88.

69. Delourme R, Pilet-Nayel ML, Archipiano M, Horvais R, Tanguy X, Rouxel T, et al. A cluster of major specific resistance genes to Leptosphaeria maculans in Brassica napus. Phytopathology. 2004;94(6):578-83.

70. Fusi N, Lippert C, Lawrence ND, Stegle O. Warped linear mixed models for the genetic analysis of transformed phenotypes. Nat Commun. 2014;5(1): 4890.

71. Bolger AM, Lohse M, Usadel B. Trimmomatic: a flexible trimmer for Illumina sequence data. Bioinformatics. 2014;30(15):2114-20.

72. Davis WH. Route to hybrid soybean production: United States Patent; 1985. US 4545146. In.

73. Li H, Durbin R. Fast and accurate short read alignment with burrowswheeler transform. Bioinformatics. 2009;25(14):1754-60.

74. Pritchard JK, Stephens M, Donnelly P. Inference of population structure using multilocus genotype data. Genetics. 2000;155(2):945-59.

75. Pritchard JK, Wen W. Documentation for STRUCTURE software. Chicago: The University of Chicago Press; 2004

76. Earl DA, von Holdt BM. STRUCTURE HARVESTER: a website and program for visualizing STRUCTURE output and implementing the Evanno method. Conserv Genet Resour. 2011:4(2):359.

77. Evanno G, Regnaut S, Goudet J. Detecting the number of clusters of individuals using the software STRUCTURE: a simulation study. Mol Ecol. 2005;14(8):2611-20. 
78. Jakobsson M, Rosenberg NA. CLUMPP: a cluster matching and permutation program for dealing with label switching and multimodality in analysis of population structure. Bioinformatics. 2007;23(14):1801-6.

79. Bradbury PJ, Zhang Z, Kroon DE, Casstevens TM, Ramdoss Y, Buckler ES.

TASSEL: software for association mapping of complex traits in diverse samples. Bioinformatics. 2007;23(19):2633-5.

80. Storey JD. A direct approach to false discovery rates. J Royal Stat Soc Series B. 2002;64(3):479-98.

\section{Publisher's Note}

Springer Nature remains neutral with regard to jurisdictional claims in published maps and institutional affiliations.

Ready to submit your research? Choose BMC and benefit from:

- fast, convenient online submission

- thorough peer review by experienced researchers in your field

- rapid publication on acceptance

- support for research data, including large and complex data types

- gold Open Access which fosters wider collaboration and increased citations

- maximum visibility for your research: over $100 \mathrm{M}$ website views per year

At $\mathrm{BMC}$, research is always in progress.

Learn more biomedcentral.com/submissions 